\title{
$N$-Hydroxyphthalimide Immobilized on Poly(HEA-co-DVB) as Catalyst for Aerobic Oxidation Processes
}

\author{
Piotr Lątka $^{1} \cdot$ Kornela Kasperczyk $^{2} \cdot$ Beata Orlińska $^{2} \cdot$ Marek Drozdek $^{1}$. \\ Bożena Skorupska ${ }^{3} \cdot$ Ewa Witek $^{1}$
}

Received: 30 May 2016 / Accepted: 27 July 2016 / Published online: 22 August 2016

(C) The Author(s) 2016. This article is published with open access at Springerlink.com

\begin{abstract}
In the present study, poly(HEA-co-DVB) was synthesized (loading of $\mathrm{OH}$ groups: $8.07 \mathrm{mmol}$ $\mathrm{OH} / \mathrm{g}$, crosslinking degree: 6\% DVB) and used for $N$-hydroxyphthalimide (NHPI) immobilization via ester

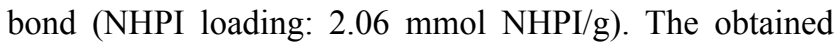
polymeric support and poly(HEA-co-DVB)/NHPI catalyst were characterized by FT-IR and XPS spectroscopy, elemental analysis, thermogravimetry and particle size measurement. The novel polymer-supported NHPI catalyst
\end{abstract}

was tested in aerobic oxidation of p-methoxytoluene and $\alpha$-methylstyrene. The studied reactions were carried out in the presence of AIBN and/or Co(II) salt without solvent or in acetic acid as solvent. It was found that the obtained polymer-supported NHPI catalyst showed the best catalytic performance, which was attributed to a high content of accessible NHPI moieties. The recovery and recycling of the obtained HEA/DVB-NHPI was only possible in reactions proceeded in solvent-free conditions.

Piotr Łątka

piotr.latka@uj.edu.pl

1 Faculty of Chemistry, Jagiellonian University, Ingardena 3, 30-060 Kraków, Poland

2 Department of Chemical Organic Technology and Petrochemistry, Silesian University of Technology, Krzywoustego 4, 44-100 Gliwice, Poland

3 Institute of Non-ferrous Materials, Mineral Processing and Waste Utilization Department, Sowińskiego 5, 44-100 Gliwice, Poland 


\section{Graphical Abstract}

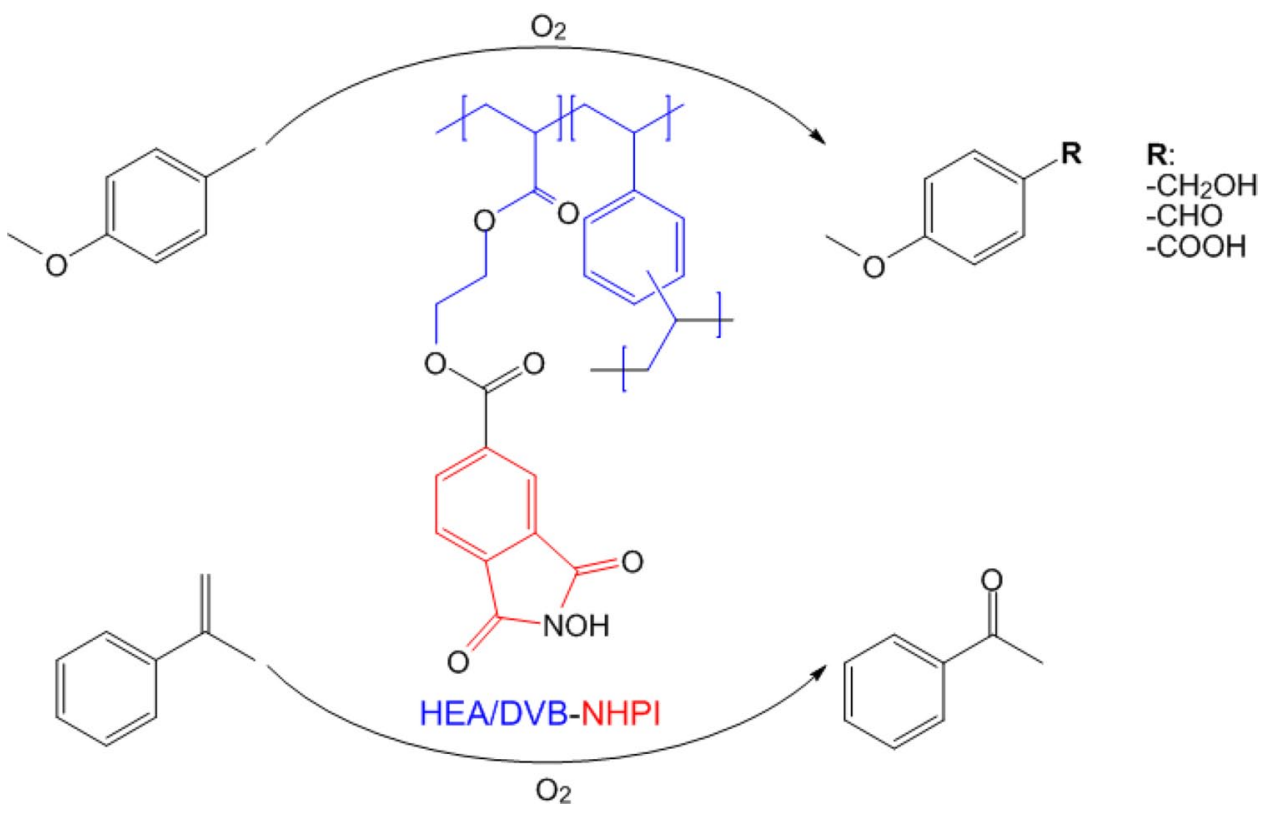

Keywords Immobilized $N$-hydroxyphthalimide · Poly(HEA-co-DVB) $\cdot$ Hydrocarbon oxidation

\section{Introduction}

$\mathrm{N}$-hydroxyphthalimide (NHPI) has been known as a valuable catalyst for aerobic oxidation of various organic compounds [1-3]. Its catalytic effect has been demonstrated among others in oxidation of alkylaromatics, such as toluene, ethylbenzene, cumene and their derivatives, to respective alcohols, ketones, carboxylic acids or hydroperoxides. Recently NHPI was also applied as catalyst for oxidative cleavage of $\alpha$-methylstyrenes [4]. The activity of NHPI is related to formation of phthalimide $N$-oxyl radical (PINO) that abstract hydrogen from substrate as shown in Scheme 1 [5]. Rate of H-abstraction by PINO is higher than by peroxyl radical in autocatalytic oxidation [e.g. rate constants for $\mathrm{H}$-abstraction from toluene by PINO and ROO are 0.08 and $0.21\left(\mathrm{~mol}^{-1} \mathrm{~s}^{-1}\right)$ at $25^{\circ} \mathrm{C}$, respectively] [6]. Additionally the catalytic effect is a result of the lower termination rate because of ROO- radicals' reaction with NHPI in place and of their recombination to stable products.

PINO formation is usually facilitated by additives such as: transition metals [7, 8], azo-compounds [9-11], peroxides [12, 13], aldehydes [14], enzymes [15, 16] and others [17]. For instance, when the most popular combination, i.e. NHPI and Co(II) salt, was applied in toluene oxidation with oxygen, benzoic acid was obtained in yield of $81 \%$ at $25^{\circ} \mathrm{C}(0.1 \mathrm{MPa}, 20 \mathrm{~h})$ [18]. In industry, benzoic acid is obtained in the presence of Amoco catalyst at significantly higher temperature $\left(190^{\circ} \mathrm{C}, 1.5 \mathrm{MPa}\right)$. The role of transition metal salts is initiation of reaction by PINO generation as well as catalyzing the decomposition of formed peroxy compounds into stable products as shown in reactions Eqs. 2 and 6 [18]. Metal-free additives, such as azo-compounds, peroxides and aldehydes, act only as initiators and impact on the PINO generation.

$\mathrm{Co}^{\mathrm{II}} \stackrel{\mathrm{O}_{2}}{\rightarrow} \mathrm{Co}{ }^{\mathrm{III}} \mathrm{OO}$

$\mathrm{Co}{ }^{\mathrm{III}} \mathrm{OO}+\mathrm{NHPI} \rightarrow \mathrm{Co}{ }^{\mathrm{III}} \mathrm{OOH}+\mathrm{PINO}$

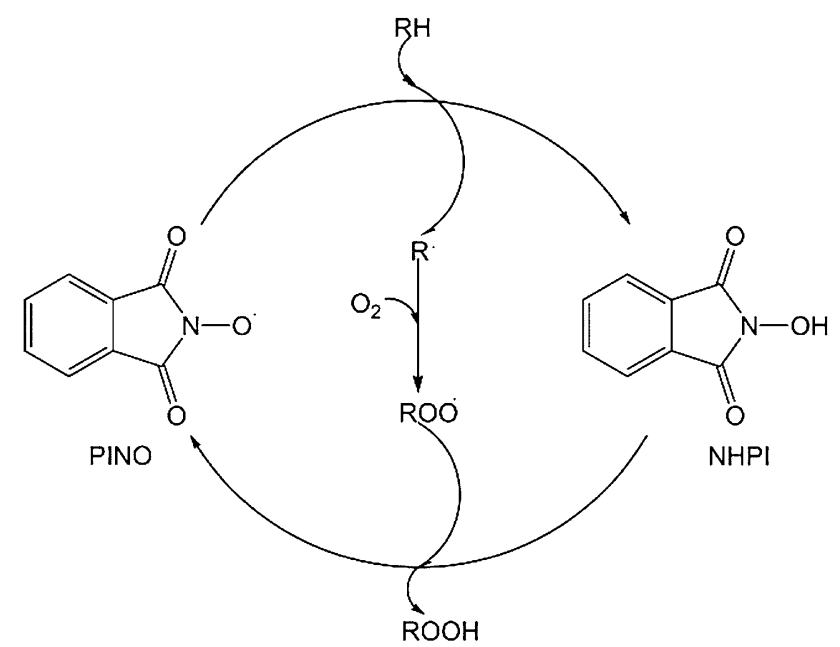

Scheme 1 Mechanism of hydrocarbon oxidation in the presence of NHPI [5] 
$\mathrm{Ar}-\mathrm{CH}_{3}+\mathrm{PINO} \rightarrow \mathrm{Ar}-\mathrm{CH}_{2}+\mathrm{NHPI}$

$\mathrm{Ar}-\mathrm{CH}_{2} \stackrel{\mathrm{O}_{2}}{\rightarrow} \mathrm{Ar}-\mathrm{CH}_{2} \mathrm{OO}$

$\mathrm{Ar}-\mathrm{CH}_{2} \mathrm{OO}+\mathrm{NHPI} \rightarrow \mathrm{Ar}-\mathrm{CH}_{2} \mathrm{OOH}+\mathrm{PINO}$

$\mathrm{Co}+\mathrm{Ar}-\mathrm{CH}_{2} \mathrm{OOH} \rightarrow \rightarrow \mathrm{Co}{ }^{\mathrm{III}}+\mathrm{Ar}-\mathrm{CH}_{2} \mathrm{OOH}$

Recently, much attention has been paid to heterogeneous catalysts. Application of both immobilized NHPI and metal co-catalyst or combination of homogeneous NHPI and immobilized transition metal co-catalysts has been reported. These catalytic systems are especially attractive due to simple separation from the reaction mixture. Examples of heterogeneous NHPI catalysts include NHPI immobilized on silica gel by physical interaction [19], NHPI immobilized by chemical bonds on silica gel [20, 21], polystyrene [22], copolymer microspheres of glycidyl and methyl methacrylate (GMA/MMA) [23] or glycidoxypropyl-SBA-15 [24] and NHPI incorporated into metal organic framework [25-29]. On the other hand, silica supported cobalt(II) [30, 31], cobalt and manganese supported hexagonal mesoporous silicas [32] or cobalt Shiff base complex anchored on starch-coated magnetic nanoparticles [33] were also examined in the presence of homogeneous NHPI. The activity of these catalytic systems was demonstrated in aerobic oxidations of cyclohexane and other cyclic hydrocarbons $[19,25,27-29,32]$, toluenes [20-22, $24]$, ethylbenzenes [23, 25, 30, 31, 33], styrenes [26] as well as other alkyl aromatic compounds [29, 31, 33] and benzylic alcohols [33]. For example, when toluene was oxidized with oxygen in the presence of both NHPI and $\mathrm{Co}(\mathrm{II})$ chemically bonded to silica gel in $\mathrm{AcOH}$ as solvent, conversion of $18 \%$ was achieved $\left(100^{\circ} \mathrm{C}, 0.1 \mathrm{MPa}, 20 \mathrm{~h}\right)$ [20]. Similar conversion was obtained when toluene was oxidized under pressure of oxygen in the presence of $\mathrm{N}, \mathrm{N}$ dihydroxypyromellitimide (NDHPI) supported on glycidoxypropyl-SBA-15 in $\mathrm{MeCN}\left(\mathrm{Co}(\mathrm{II}), 70^{\circ} \mathrm{C}, 1.6 \mathrm{MPa}\right.$, $7 \mathrm{~h}$ ) [24]. When NHPI immobilized on commercial polystyrene via amide or ester bonds was applied in $p$-methoxytoluene oxidation with oxygen in $\mathrm{AcOH}$ or solvent-free condition conversions of 18 and $2.3 \%$, respectively, were achieved $\left(\mathrm{Co}(\mathrm{II}), 80^{\circ} \mathrm{C}, 0.1 \mathrm{MPa}, 6 \mathrm{~h}\right)$ [22]. The final effect of NHPI immobilization on a solid carrier by means of covalent bond depends on quantity, quality and distribution of functional groups in a carrier. The cross-linked and thus insoluble synthetic functional polymers are attractive as solid carriers for catalysts and biocatalysts, because they can be formed into grains of predetermined shape and dimensions. The pendant functional groups are used for the formation of stable covalent bonds with molecules of a catalyst. The pendant functional groups in commercially available polystyrenes, such as $\mathrm{NH}_{2}$ and $\mathrm{OH}$, have been previously used by us to immobilize trimellitic anhydride acid chloride (TAC), which is the precursor of NHPI [22]. Nevertheless, commercially available polymers contain only small amount of these functional groups. In the polymeric beads based on cross-linked 2-hydroxyethylacrylate (HEA), containing high density of hydroxyethyl groups can be employed to immobilize of NHPI via ester bonds. 2-Hydroxyethylacrylate (HEA) is the closest analogue of 2-hydroxyethylmethacrylate (HEMA). Vinyl monomers are also commercially available and are commonly used for synthesis of three-dimensional hydrophilic copolymer networks called hydrogels, synthesized via three-dimensional free-radical polymerization (TFRP) [34]. Hydrogels HEMA and HEA-based, due to good mechanical properties, no cytotoxicity, biocompatibility and high thermal stability are applied as biomaterials and coatings [35-39]. In particular, the HEMA is the subject of numerous original papers and monographs on the synthesis, properties and applications of HEMA-based hydrogels, such as the reviewed article of Montheard et al. [40]. The first and the most spectacular application of HEMA-based hydrogels are soft contact lenses developed by Otto Wichterle in 1960 [41-44]. The immobilization of NHPI on the polymer carriers based on HEMA and HEA is not reported in literature, but HEMA-based polymers have been used to immobilize the enzymes [45-47]. Three-dimensional, freeradical copolymerization of HMA and HEA with divinyl monomers called cross-linkers can be carried out using a variety of techniques: bulk cross-linking copolymerization $[39,48]$, solution cross-linking copolymerization [49, 50] and suspension cross-linking copolymerization [51]. They showed that HEMA-based hydrogel cross-linked of divinylbenzene (DVB) was the smallest deformable polymer tested in this study and had the highest value of Young's modulus. According to these results, it appears that DVB is the appropriate cross-linker for the synthesis of HEAbased carrier to immobilize NHPI.

In this paper, the application of poly(HEA-co-DVB) as support for NHPI has been reported for the first time. In contrary to previously reported the polystyrene-supported NHPI [22] and GMA/MMA-supported NHPI [23], the new catalyst HEA/DVB-NHPI is characterized by higher NHPI loading. The formed linker is longer than in polystyrene and similar to GMA/MMA supported N$\mathrm{OH}$ groups. There is no data on NHPI loading in other described chemically immobilized NHPI [20, 21, 24]. Herein, activity of this new solid HEA/DVB-NHPI has been studied in oxidation reactions of $p$-methoxytoluene and $\alpha$-methylstyrene. 


\section{Experimental}

\subsection{Materials}

2-Hydroxyethylacrylate (HEA, 96\%, Aldrich), divinylbenzene (technical 55\%, Sigma-Aldrich), benzoyl peroxide $(75 \%$, Sigma-Aldrich), trimellitic anhydride chloride (98\%, Sigma-Aldrich), hydroxylamine hydrochloride (98\%, Sigma-Aldrich) $N$-Hydroxyphthalimide (97\%, Sigma-Aldrich), 2,2'-azobis(2-methylpropionitrile) (AIBN, $98 \%$, Acros Organics), $\mathrm{Co}(\mathrm{OAc})_{2} \cdot \mathrm{H}_{2} \mathrm{O}$ (pure p. a., $\mathrm{POCH}$ ), were used as received. Solvents Dichloromethane (DCM, Pure p. a., POCH), Pyridine (Pure p. a., POCH), $N, N$-dimethylformamide (DMF, Pure p. a., POCH), tetrahydrofuran (THF, Pure p. a., POCH), diethyl ether $\left(\mathrm{Et}_{2} \mathrm{O}\right.$ Pure p. a., POCH), methanol (MeOH Pure p. a., POCH), dichloroethane (DCE Pure p. a., $\mathrm{POCH})$, acetic acid $(\mathrm{AcOH}$, Pure p.a., $\mathrm{POCH})$, acetonitrile ( $\mathrm{MeCN}$, pure p. a., $\mathrm{POCH})$. Reagents were used as received without further purification. Solvents used in catalytic tests such as $p$-methoxytoluene (99.8\%, Acros Organics), $\alpha$-methylstyrene (98\%, Sigma-Aldrich) were purified and dried with standard methods.

\subsection{Preparation of Catalyst}

\subsubsection{Polymerization of 2-Hydroxyethylacrylate with Divinylbenzene}

Copolymer of HEA and DVB (poly(HEA-co-DVB)) was prepared by mixing HEA $(3.00 \mathrm{~mL}, 26 \mathrm{mmol})$ and DVB (0.40 mL, $1.54 \mathrm{mmol})$, then BPO was added (0.48 g, $2 \mathrm{mmol}$ ). The solution was transferred into a $30 \mathrm{~mL}$ vial. The vial was flushed with argon and sealed. The vial was heated at $60^{\circ} \mathrm{C}$ for $6 \mathrm{~h}$. The copolymer was removed from vial, crushed, washed with DCM and dried under vacuum.As references [17], [55] and [39], [49] are duplicate, we have deleted the duplicate references and renumbered accordingly. Please check and confirm. Now is ok

FT-IR of HEA/DVB: 3392, 2947, 2877, 1721, 1448, 1393, 1239, 1239, 1159, 1073, 888, 841, 756, $741 \mathrm{~cm}^{-1}$. Elemental analysis of HEA/DVB: C 54.12\%, H 7.13\%, another $38.75 \%$.

\subsubsection{Immobilization of Trimellitic Anhydride Chloride}

The mixture of copolymer poly(HEA-co-DVB) (1.00 g), $\mathrm{DCM}(30 \mathrm{~mL})$ and pyridine $(0.83 \mathrm{~mL}, 10 \mathrm{mmol})$ was cooled to $0^{\circ} \mathrm{C}$ in ice bath. Next, solution of TAC $(2.17 \mathrm{~g}, 10 \mathrm{mmol})$ in $30 \mathrm{~mL}$ DCM was added dropwise over $1 \mathrm{~h}$. The reaction mixture was stirred for $3 \mathrm{~h}$ at $0^{\circ} \mathrm{C}$ and for additional $24 \mathrm{~h}$ at RT. The product was filtered and washed twice with $10 \mathrm{~mL}$ of solvent in the following order: DCM, DMF, THF, DCM and $\mathrm{Et}_{2} \mathrm{O}$. Product-copolymer poly(HEA-co-DVB) with immobilized TAC (HEA/DVB-TAC) was dried under vacuum. Next, HEA/DVB-TAC was added to a $40 \mathrm{~mL}$ mixture of pyridine: DCE $(3: 1, v / v)$, followed by the addition of hydroxylamine hydrochloride $(0.71 \mathrm{~g}, 10 \mathrm{mmol})$. The mixture was stirred for $24 \mathrm{~h}$ at $75^{\circ} \mathrm{C}$. The product was filtered and washed with $\mathrm{H}_{2} \mathrm{O}(2 \times 10 \mathrm{~mL}), \mathrm{MeOH}(2 \times 10 \mathrm{~mL}), \mathrm{DMF}(2 \times 10 \mathrm{~mL})$, DMF/water $(1: 1, \mathrm{v} / \mathrm{v}, 2 \times 10 \mathrm{~mL}), \mathrm{DMF}(1 \times 10 \mathrm{~mL}), \mathrm{THF}$ $(3 \times 10 \mathrm{~mL}), \mathrm{DCM}(2 \times 10 \mathrm{~mL})$, and $\mathrm{Et}_{2} \mathrm{O}(2 \times 10 \mathrm{~mL})$ and dried under vacuum. Copolymer poly(HEA-co-DVB) with immobilized NHPI (HEA/DVB-NHPI) was obtained.

FT-IR of HEA/DVB-TAC: 2950, 1852, 1777, 1725, 1456, 1296, 1266, 1228, 1166, 1102, 930, 888, 786, 717, $695 \mathrm{~cm}^{-1}$. Elemental analysis of HEA/DVB-TAC: C $53.81 \%$, H $4.89 \%$, another $41.30 \%$.

FT-IR of HEA/DVB-NHPI: 3218, 2937, 1785, 1725, 1454, 1336, 1292, 1253, 1185, 1159, 1104, 1062, 989, 921, 882, 770, $706 \mathrm{~cm}^{-1}$. Elemental analysis of HEA/DVBNHPI: C 56.13\%, H $4.91 \%$, N $2.89 \%$, another $36.07 \%$.

Swelling ratio of HEA/DVB-NHPI was determined at $8.4 \%$ in $\mathrm{AcOH}$ as a solvent, while there was no swelling of
Fig. 1 Particle size distribution of HEA/DVB-NHPI

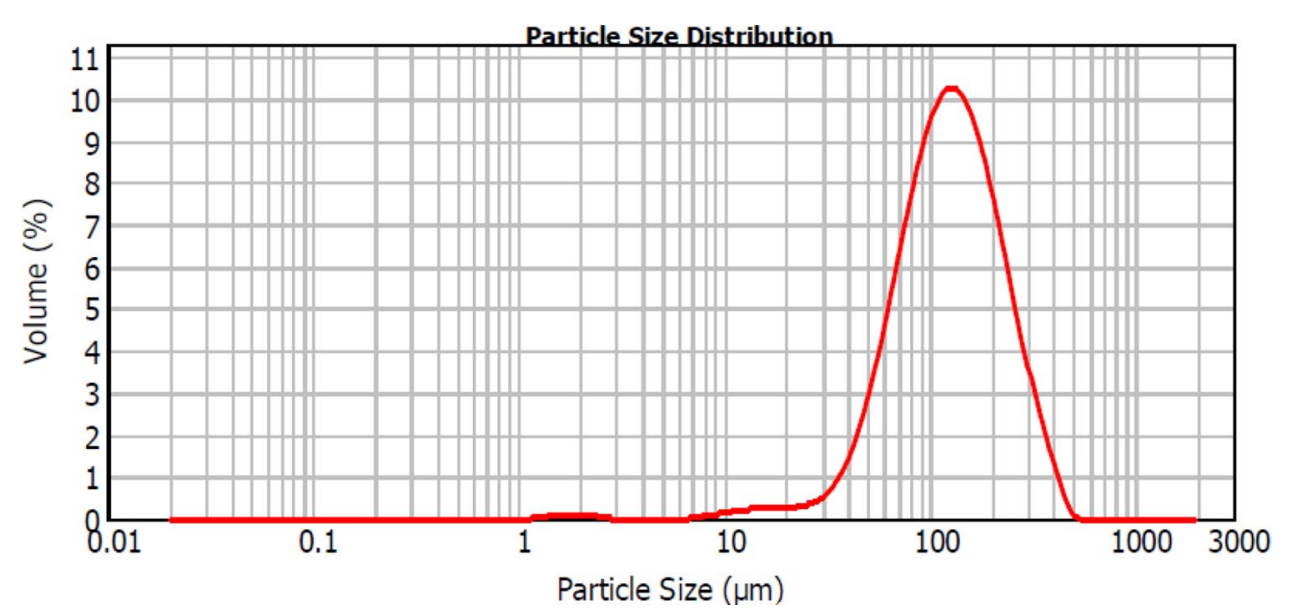


polymer in $p$-methoxytoluene and $\alpha$-methylstyrene observed. Particle size was measured and mean size was $143 \mu \mathrm{m}$ (D $[3,4])$, distribution of particles was in the range between 56.7 and $255.8 \mu \mathrm{m}(\mathrm{d}(0.1): 56.667 \mu \mathrm{m} ; \mathrm{d}(0.5): 124.8 \mu \mathrm{m}$; $\mathrm{d}(0.9): 255.8 \mu \mathrm{m})$ (Fig. 1). Specific surface area of obtained catalyst was $0.0721 \mathrm{~m}^{2} / \mathrm{g}$.

\subsection{Typical Procedure for Oxidation Without Solvent}

The oxidation reactions were performed in a gasometric apparatus described in Ref. [52]. $p$-Methoxytoluene $(2.0 \mathrm{~mL}$, $15.9 \mathrm{mmol})$ or $\alpha$-methylstyrene $(2.0 \mathrm{~mL}, 16.3 \mathrm{mmol})$, HEA/ DVB-NHPI (0.10 g), AIBN $(0.03 \mathrm{mmol})$ and $/$ or $\mathrm{Co}(\mathrm{OAc})_{2}$. $\mathrm{H}_{2} \mathrm{O}(0.02 \mathrm{mmol})$ were placed in a flask connected to a gas burette filled with oxygen under atmospheric pressure. The mixture was heated up to reaction temperature and stirred at $1400 \mathrm{rpm}$ for 6 or $15 \mathrm{~h}$. The oxygen uptake was measured and recalculated to the conditions of $0^{\circ} \mathrm{C}$ and $1 \mathrm{~atm}$. After the reaction, the catalyst was separated through filtration, washed with MeCN and DCM and then recycled. After recycling HEA/DVB-NHPI was characterized by FT-IR. The oxidation products were determined by GC analysis.

\subsection{Typical Procedure for Oxidation in $\mathrm{AcOH}$}

$p$-Methoxytoluene $(0.63 \mathrm{~mL}, 5 \mathrm{mmol}), \mathrm{AcOH}(10 \mathrm{~mL}), \mathrm{HEA} /$ DVB-NHPI $(0.10 \mathrm{~g})$, cobalt(II) acetate $\left(\mathrm{Co}(\mathrm{OAc})_{2} \cdot \mathrm{H}_{2} \mathrm{O}\right.$, $0.02 \mathrm{mmol})$ and AIBN $(0.03 \mathrm{mmol})$ were placed in a flask connected to a gasometric apparatus. Reaction was conducted at $80^{\circ} \mathrm{C}$ for $6 \mathrm{~h}$. The oxidation procedure was the same as for the oxidation described above.

\subsection{Analytical Methods}

Infrared spectra were recorded on a Nicolet 6700 FT-IR Spectrometer. Elemental analysis was performed on a CHNS Vario Micro Cube. GC analysis of products of $p$-methoxytoluene oxidation was performed using an Agilent Technologies 7890A/5975C Gas Chromatography (HP-5 MS capillary column, $30 \mathrm{~m} \times 0.25 \mathrm{~mm} \times 0.25 \mu \mathrm{m}$, helium $1.2 \mathrm{~mL} /$ $\mathrm{min}$ ) with FID detector. The injection port temperature was

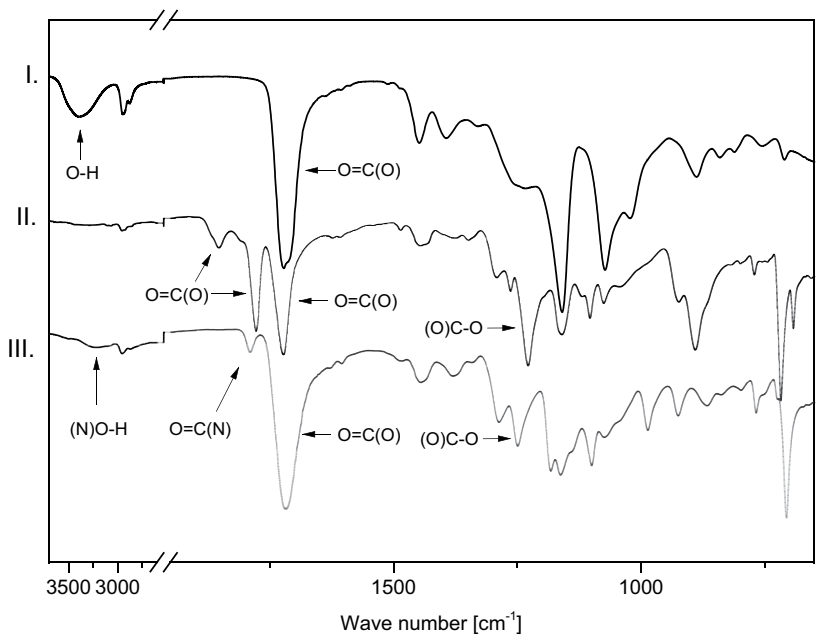

Fig. 2 FT-IR spectra of HEA/DVB (I), HEA/DVB-TAC $(I I)$ and HEA/DVB-NHPI (III)

$250^{\circ} \mathrm{C}$. The detector temperature was $280^{\circ} \mathrm{C}$. The temperature program was: hold at $50^{\circ} \mathrm{C}$ for $5 \mathrm{~min}$, ramp at $5^{\circ} \mathrm{C} \mathrm{min}^{-1}$ to $200^{\circ} \mathrm{C}$, then ramp at $25^{\circ} \mathrm{C} \mathrm{min}^{-1}$ to $300^{\circ} \mathrm{C}$ for $5 \mathrm{~min}$. Conversion and selectivity were calculated based on internal standard-cyclohexanone. GC analysis of products of $\alpha$-methylstyrene oxidation was performed using a Hewlett 5890 Series II Gas Chromatography (Zebron ZB5HT capillary column, $30 \mathrm{~m} \times 0.32 \mathrm{~mm} \times 0.1 \mu \mathrm{m}$, helium $48 \mathrm{kPa}$ ) with FID detector. The injection port temperature was $280^{\circ} \mathrm{C}$. The detector temperature was $280^{\circ} \mathrm{C}$. The temperature program was: hold at $70^{\circ} \mathrm{C}$ for $2 \mathrm{~min}$, ramp at $5^{\circ} \mathrm{C} \mathrm{min}^{-1}$ to $100^{\circ} \mathrm{C}$, then ramp at $20^{\circ} \mathrm{C} \mathrm{min}^{-1}$ to $250^{\circ} \mathrm{C}$ for $2 \mathrm{~min}$. Conversion and selectivity were calculated based on internal standard-naphthalene.

Thermogravimetric analysis (TG) was carried out in SDT q600 thermobalance (TA instrument). The measurement was performed in corundum crucibles using about $10 \mathrm{mg}$ of sample. The decomposition of the organic part was monitored in an air flow $(100 \times \mathrm{mL} / \mathrm{min})$ while the temperature was increased from 30 to $1000^{\circ} \mathrm{C}$ at a rate of $20^{\circ} \mathrm{C} \mathrm{min}{ }^{-1}$. Particle size and surface area were measured on MASTERSIZER 2000 MALVERN INSTRUMENTS. The X-ray photoelectron spectra (XPS) were acquired
Scheme 2 Immobilization of $N$-hydroxyphthalimide on synthesized copolymer poly(HEA-co-DVB)

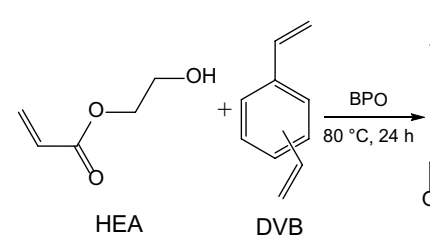

HEA/DVB
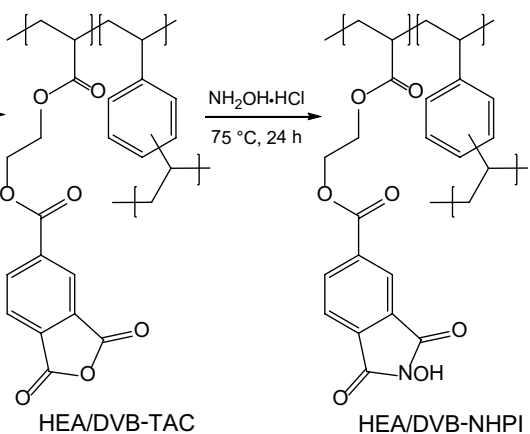


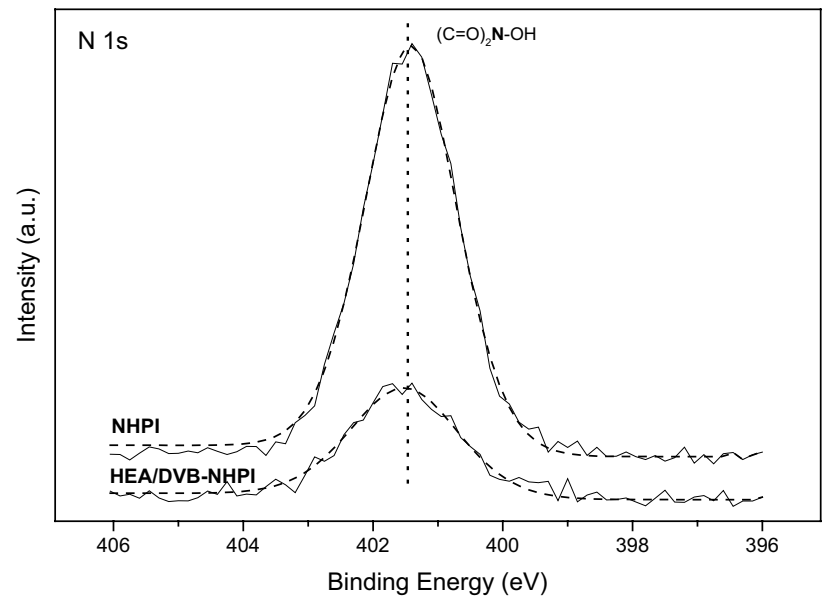

Fig. $3 \mathrm{~N} 1 \mathrm{~s}$ high-resolution XPS spectra of NHPI and HEA/ DVB-NHPI

using a Prevac photoelectron spectrometer equipped with a hemispherical VG SCIENTA R3000 analyzer. The spectra were taken using a monochromatized aluminum source $\mathrm{Al} \mathrm{K} \alpha(\mathrm{E}=1486.6 \mathrm{eV})$ and a low-energy electron flood gun (FS40A-PS) to compensate for the charge accumulation on the surface of nonconductive samples. Spectra were processed and deconvoluted using CasaXPS software.

\section{Results and Discussion}

In this paper, new polymer-supported NHPI was obtained and examined in selected oxidation reactions. Copolymer poly(HEA-co-DVB) was used to immobilized NHPI via ester bond.

\subsection{Preparation of Catalyst}

Copolymer poly(HEA-co-DVB) was synthesized by polymerization of HEA and DVB, then NHPI was immobilized on prepared HEA/DVB as shown in Scheme 2. The FT-IR spectrum (Fig. 2I) of HEA/DVB showed characteristic peaks of hydroxyl and carbonyl groups at 3392 and $1721 \mathrm{~cm}^{-1}$, respectively. After immobilization of TAC, the peak of hydroxyl group at $3392 \mathrm{~cm}^{-1}$ disappeared on FT-IR spectrum (Fig. 2II). The FT-IR spectrum of Fig. 2II. showed new peaks at 1852 and $1777 \mathrm{~cm}^{-1}$ corresponding to anhydride groups [53] and $1228 \mathrm{~cm}^{-1}$ —stretching vibrations of $\mathrm{C}-\mathrm{O}$ bond. The appearance of new anhydride bonds as well as disappearance of hydroxyl group bond confirmed immobilization of TAC. FT-IR spectrum of final product-HEA/DVB-NHPI showed peak at $3218 \mathrm{~cm}^{-1}$ (Fig. 2III) corresponding to hydroxyl group in obtained $\mathrm{N}$-hydroxyphthalimide moiety. Moreover, characteristic bond of anhydride group at $1852 \mathrm{~cm}^{-1}$ disappeared and carbonyl bond at $1777 \mathrm{~cm}^{-1}(\mathrm{O}=\mathrm{C}(\mathrm{O}))$ shifts to $1785 \mathrm{~cm}^{-1}$ $(\mathrm{O}=\mathrm{C}(\mathrm{N}))$. Peaks at 3218 and $1785 \mathrm{~cm}^{-1}$ confirmed formation of $N$-hydroxyl group and obtaining immobilized form of $N$-hydroxyphthalimide [17, 54].

The XPS analysis was performed to confirm the presence of catalytic centers on the surface of material. The presence of $\mathrm{N} 1 \mathrm{~s}$ peak in obtained catalyst confirmed the immobilization of NHPI onto polymeric support. The high-resolution $\mathrm{N} 1 \mathrm{~s}$ spectra collected for NHPI as well as for HEA/DVBNHPI are displayed on Fig. 3. The N 1 s core level spectra were fitted with only one component. In the case of NHPI binding energy of $\mathrm{N}-\mathrm{OH}$ is $401.4 \mathrm{eV}$ and in HEA/DVBNHPI binding energy of $\mathrm{N}-\mathrm{OH}$ group is $401.5 \mathrm{eV}$.
Fig. 4 Thermogravimetric spectrum of HEA/DVB-NHPI

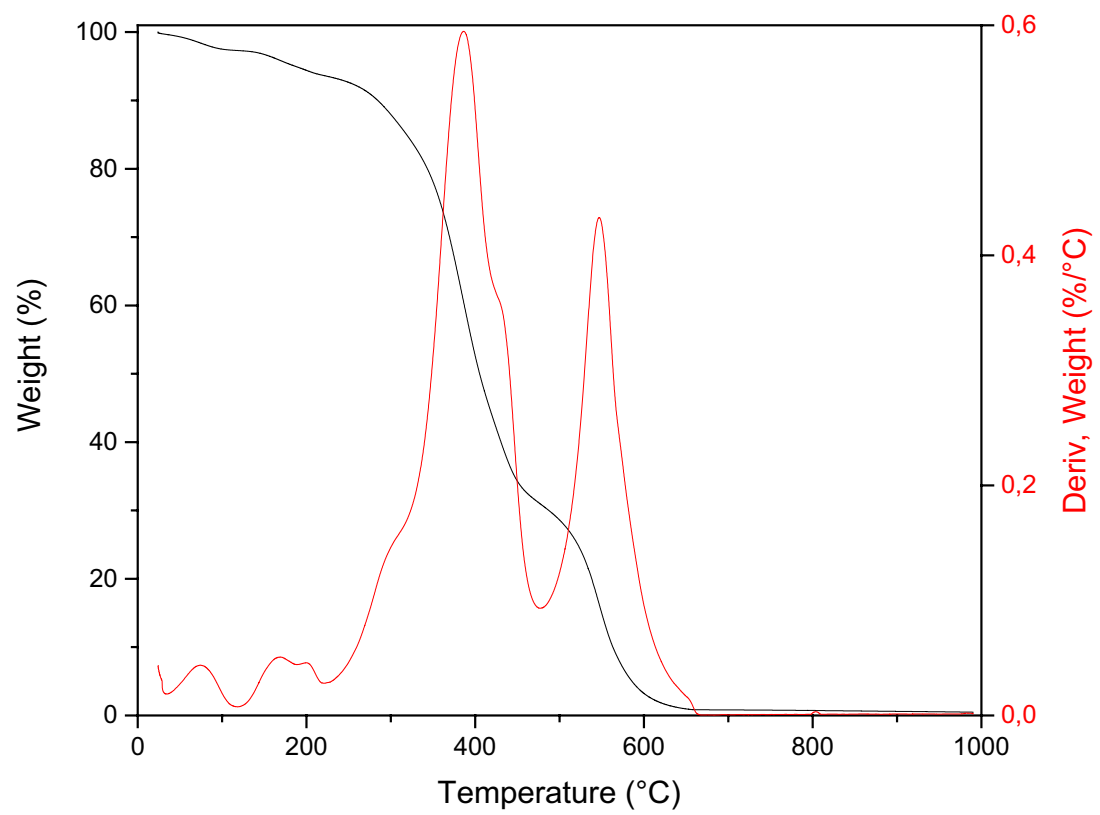


Table 1 Oxidation of $p$-methoxytoluene in the presence of HEA/DVB-NHPI

\begin{tabular}{|c|c|c|c|c|c|c|c|c|}
\hline \multirow[t]{2}{*}{ Entry } & \multicolumn{2}{|c|}{$p$-Methoxytoluene } & \multirow[t]{2}{*}{ Temperature $\left({ }^{\circ} \mathrm{C}\right)$} & \multirow[t]{2}{*}{ Time (h) } & \multirow[t]{2}{*}{$\mathrm{Co}(\mathrm{OAc})_{2} \cdot \mathrm{H}_{2} \mathrm{O}(\mathrm{mmol})$} & \multicolumn{2}{|c|}{ HEA/DVB-NHPI } & \multirow[t]{2}{*}{$\mathrm{O}_{2}$ consumed $(\mathrm{mmol})$} \\
\hline & $\mathrm{mmol}$ & $\mathrm{mL}$ & & & & Recycle & $\mathrm{g}$ & \\
\hline 1 & $5.0^{\mathrm{a}}$ & 0.63 & 80 & 6 & 0.02 & - & - & 0.02 \\
\hline 2 & $5.0^{\mathrm{a}}$ & 0.63 & 80 & 6 & 0.02 & 0 & 0.10 & 3.33 \\
\hline 3 & $5.0^{\mathrm{a}}$ & 0.63 & 80 & 6 & 0.02 & 1 & 0.10 & 0.25 \\
\hline 4 & $5.0^{\mathrm{a}}$ & 0.63 & 80 & 6 & 0.02 & 2 & 0.08 & 0.00 \\
\hline 5 & 15.9 & 2.0 & 70 & 6 & 0.02 & - & - & 0.04 \\
\hline 6 & 15.9 & 2.0 & 70 & 6 & 0.02 & 0 & 0.10 & 0.14 \\
\hline 7 & 15.9 & 2.0 & 70 & 6 & 0.02 & 1 & 0.09 & 0.13 \\
\hline 8 & 15.9 & 2.0 & 80 & 6 & 0.0 & - & - & 0.03 \\
\hline 9 & 15.9 & 2.0 & 80 & 6 & 0.0 & 0 & 0.10 & 0.12 \\
\hline 10 & 15.9 & 2.0 & 80 & 6 & 0.02 & - & - & 0.04 \\
\hline 11 & 15.9 & 2.0 & 80 & 6 & 0.02 & 0 & 0.025 & 0.06 \\
\hline 12 & 15.9 & 2.0 & 80 & 6 & 0.02 & 0 & 0.05 & 0.09 \\
\hline 13 & 15.9 & 2.0 & 80 & 6 & 0.02 & 0 & 0.10 & 0.17 \\
\hline 14 & 15.9 & 2.0 & 80 & 6 & 0.02 & 0 & 0.15 & 0.11 \\
\hline 15 & 15.9 & 2.0 & 80 & 6 & 0.02 & - & - & 0.04 \\
\hline 16 & 15.9 & 2.0 & 80 & 6 & 0.02 & 0 & 0.10 & 0.17 \\
\hline 17 & 15.9 & 2.0 & 80 & 6 & 0.02 & 1 & 0.09 & 0.62 \\
\hline 18 & 15.9 & 2.0 & 80 & 6 & 0.02 & 2 & 0.09 & 0.47 \\
\hline 19 & 15.9 & 2.0 & 80 & 6 & 0.02 & 3 & 0.08 & 0.48 \\
\hline 20 & 15.9 & 2.0 & 80 & 15 & 0.02 & - & - & 0.71 \\
\hline 21 & 15.9 & 2.0 & 80 & 15 & 0.02 & 0 & 0.10 & 1.01 \\
\hline 22 & 15.9 & 2.0 & 90 & 6 & 0.02 & - & - & 0.92 \\
\hline 23 & 15.9 & 2.0 & 90 & 6 & 0.02 & 0 & 0.10 & 1.34 \\
\hline 24 & 15.9 & 2.0 & 90 & 6 & 0.02 & 1 & 0.10 & 0.93 \\
\hline 25 & 15.9 & 2.0 & 90 & 6 & 0.02 & 2 & 0.09 & 0.80 \\
\hline
\end{tabular}

HEA/DVB-NHPI (0.206 mmol of NHPI), AIBN (0.03 mmol), $1 \mathrm{~atm}, 1400 \mathrm{rpm}$

${ }^{\mathrm{a}}$ Reaction in $\mathrm{AcOH}(10 \mathrm{~mL})$

Based on elemental analysis, loading of hydroxyethyl groups in HEA/DVB and cross-linking degree were calculated as $8.07 \mathrm{mmol} \mathrm{OH} / \mathrm{g}$ and $6 \% \mathrm{DVB}$, respectively. The results of elemental analysis were also used to calculate NHPI loading of $2.06 \mathrm{mmol} \mathrm{NHPI/g}$.

Loading of immobilized NHPI was lower than expected based on high amount of - $\mathrm{OH}$ loading in synthesized support. However, NHPI loading and cross-linking degree of HEA/DVB-NHPI were higher in comparison to reported NHPI supported on commercially available (chloromethyl)polystyrene via ester bond (maximum loading $1.65 \mathrm{mmol} \mathrm{NHPI/g}$, maximum cross-linking degree $5.5 \%$ DVB) [22]. In contrary to our obtained heterogeneous NHPI, GMA/MMA-NHPI microspheres were characterized by lower amount of NHPI previously bonded through a Schiff base reaction $(1.1 \mathrm{mmol} / \mathrm{g})$ and ethylene glycol dimethacrylate as cross-linker (no data of cross-linking degree) [23]. There is no data on NHPI loading in other described chemically immobilized NHPI $[20,21,24]$.
Stability of polymer was investigated by Thermogravimetric analysis (Fig. 4). TG spectra can be distinguished by two regions of mass loss: (I) up to $150^{\circ} \mathrm{C}$ which corresponding to physically adsorbed water, (II) above $150^{\circ} \mathrm{C}$ which corresponding to desorption and oxidation of material. Three stages of weight loss in TG curve over $150^{\circ} \mathrm{C}$ were observed: (a) area of $150-250^{\circ} \mathrm{C}$ showed start of catalyst decomposition, (b) area between 250 and $500^{\circ} \mathrm{C}$ showed major weight loss which were characteristic for carbonization of sample and c) area above $500^{\circ} \mathrm{C}$ was characterized as carbon oxidation. TG analysis demonstrated stability of obtained immobilized NHPI in temperature of performed oxidation reactions.

\subsection{Catalytic Tests of HEA/DVB-NHPI}

$p$-Methoxytoluene and $\alpha$-methylstyrene were used as starting material for catalytic tests of obtained new polymersupported NHPI. Oxidation of model compounds was performed in the presence of HEA/DVB-NHPI both in polar 
Table 2 Oxidation of $\alpha$-methylstyrene in the presence of HEA/DVBNHPI

\begin{tabular}{|c|c|c|c|c|c|c|}
\hline \multirow[t]{2}{*}{ Entry } & \multirow{2}{*}{$\begin{array}{l}\text { Tem- } \\
\text { pera- } \\
\text { ture } \\
\left({ }^{\circ} \mathrm{C}\right)\end{array}$} & \multirow{2}{*}{$\begin{array}{l}\text { Time } \\
\text { (h) }\end{array}$} & \multirow{2}{*}{$\begin{array}{l}\mathrm{Co}(\mathrm{OAc})_{2} \cdot \mathrm{H}_{2} \mathrm{O} \\
(\mathrm{mmol})\end{array}$} & \multicolumn{2}{|c|}{ HEA/DVB-NHPI } & \multirow{2}{*}{$\begin{array}{l}\mathrm{O}_{2} \\
\text { con- } \\
\text { sumed } \\
(\mathrm{mmol})\end{array}$} \\
\hline & & & & Recycle & g & \\
\hline 1 & 70 & 6 & 0.0 & - & - & 3.4 \\
\hline 2 & 70 & 6 & 0.0 & 0 & 0.10 & 4.6 \\
\hline 3 & 70 & 6 & 0.0 & 1 & 0.10 & 5.7 \\
\hline 4 & 70 & 6 & 0.0 & 2 & 0.10 & 5.4 \\
\hline 5 & 70 & 15 & 0.0 & - & - & 6.6 \\
\hline 6 & 70 & 15 & 0.0 & 0 & 0.10 & 8.3 \\
\hline 7 & 80 & 6 & 0.0 & - & - & 5.1 \\
\hline 8 & 80 & 6 & 0.0 & 0 & 0.10 & 5.5 \\
\hline 9 & 80 & 6 & 0.0 & 1 & 0.10 & 5.8 \\
\hline 10 & 80 & 6 & 0.0 & 2 & 0.09 & 4.0 \\
\hline 11 & 80 & 6 & 0.02 & - & - & 5.1 \\
\hline 14 & 80 & 6 & 0.02 & 2 & 0.09 & 4.9 \\
\hline
\end{tabular}

$\alpha$-Methylstyrene (2 mL, $16.3 \mathrm{mmol})$, HEA/DVB-NHPI (0.206 mmol of NHPI), AIBN (0.03 mmol), $1 \mathrm{~atm}, 1400 \mathrm{rpm}$

solvent as well as in solvent-free conditions. Reactions were performed at temperature in the range of $70-90{ }^{\circ} \mathrm{C}$ in the presence of AIBN or AIBN and Co(II) salt. Oxygen uptakes were used to observe reactions progress and were collected in Tables 1 and 2. Immobilized NHPI was recycled up to three times. Inconsiderable loss of catalyst during filtration was observed due to small mesh size of catalyst and low scale of performed oxidation.

It was proved that obtained HEA/DVB-NHPI could successfully catalyzed oxidation processes of $p$-methoxytoluene and $\alpha$-methylstyrene in solvent-free conditions. Studied reactions were performed in the presence of AIBN or $\mathrm{AIBN} / \mathrm{Co}$ (II) system. AIBN was added in the amount of $0.1-0.2 \mathrm{~mol} \%$ in order to initiate the oxidation process and reduce the induction period. AIBN decomposed to alkyl radicals (2-cyanoprop-2-yl radicals) under the applied

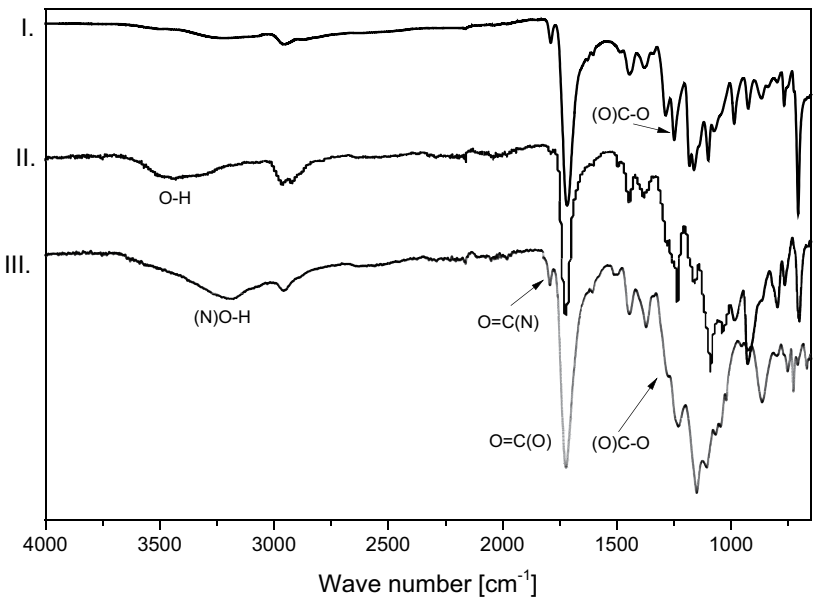

Fig. 5 FT-IR spectra of fresh HEA/DVB-NHPI (I), reused HEA/ DVB-NHPI in AcOH (II) and reused HEA/DVB-NHPI in solvent-free system (III)

conditions that could abstract hydrogen mainly from NHPI. For instance, when $p$-methoxytoluene was oxidized in the presence of HEA/DVB-NHPI and Co(II) salt without AIBN, indication period of $30 \mathrm{~min}$ was observed at $80^{\circ} \mathrm{C}$. It was reduced to 9 min after AIBN addition. Effect of Co(II) salt in oxidation of both $p$-methoxytoluene and $\alpha$-methylstyrene in the presence of HEA/DVB-NHPI was studied. When reaction of $p$-methoxytoluene with HEA/DVB-NHPI/ $\mathrm{Co}(\mathrm{II})$ system was performed the higher $\mathrm{O}_{2}$ consumption were achieved (Table 1, entries 9, 16). Additionally, induction period was reduced from 14 to $7 \mathrm{~min}$. In oxidation of $\alpha$-methylstyrene similar oxygen consumption was obtained in the presence of HEA/DVB-NHP/Co(II) system and without additive of metal salt (Table 2, entries 8,12). Similarly, no effect of Co(II) salt additive on NHPI-catalyzed oxidation of $\alpha$-methylstyrene was reported in paper [4].

The higher catalytic effect of HEA/DVB-NHPI was observed in oxidation of $p$-methoxytoluene than $\alpha$-methylstyrene. For example, consumption of $\mathrm{O}_{2}$ in $p$-methoxytoluene at $80^{\circ} \mathrm{C}$ increased up to 15.5 times

Table 3 Composition of oxidation products of $p$-methoxytoluene and $\alpha$-methylstyrene

\begin{tabular}{|c|c|c|c|c|c|c|}
\hline \multirow[t]{2}{*}{ Entry } & \multirow[t]{2}{*}{ Substrate } & \multirow[t]{2}{*}{ HEA/DVB-NHPI (g) } & \multirow[t]{2}{*}{ Conversion $^{\mathrm{c}}(\%)$} & \multicolumn{3}{|c|}{ Selectivity $^{\mathrm{c}}(\%)$} \\
\hline & & & & Aldehyde & Alcohol & Acid \\
\hline 1 & $p$-Methoxytoluene ${ }^{\mathrm{a}}$ & - & 3.8 & 44 & 37 & 19 \\
\hline \multirow[t]{2}{*}{2} & & 0.1 & 4.9 & 46 & 31 & 23 \\
\hline & & & & \multicolumn{3}{|c|}{ Acetophenone } \\
\hline 3 & $\alpha$-Methylstyrene ${ }^{b}$ & - & 61 & \multicolumn{3}{|l|}{73} \\
\hline 4 & & 0.1 & 70 & \multicolumn{3}{|l|}{66} \\
\hline
\end{tabular}

${ }^{a} p$-Methoxytoluene $(2 \mathrm{~mL}, 15.9 \mathrm{mmol}), \mathrm{Co}(\mathrm{OAc})_{2} \cdot \mathrm{H}_{2} \mathrm{O}(0.02 \mathrm{mmol}), \mathrm{AIBN}(0.03 \mathrm{mmol}), 80^{\circ} \mathrm{C} 1 \mathrm{~atm}, 1400 \mathrm{rpm}, 15 \mathrm{~h}$

${ }^{\mathrm{b}} \alpha$-Methylstyrene $(2 \mathrm{~mL}, 15.9 \mathrm{mmol}), \operatorname{AIBN}(0.03 \mathrm{mmol}), 70^{\circ} \mathrm{C} 1 \mathrm{~atm}, 1400 \mathrm{rpm}, 15 \mathrm{~h}$

${ }^{\mathrm{c}}$ Based on GC analysis 
(Table 1, entry17) in comparison to reaction performed without HEA/DVB-NHPI (Table 1, entry 15). As expected, the rate of oxidation reaction of $\alpha$-methylstyrene was higher than $p$-methoxytoluene. However, the increased of $\mathrm{O}_{2}$ consumption was lower, for example at $70^{\circ} \mathrm{C}$ increased only up to 1.7 times (Table 2, entry 3 ) in comparison to reaction without NHPI (Table 2, entry 1).

The catalytic activity of immobilized NHPI was similar in subsequent recycles (Table 1, entries 16-19; Table 2, entries 2-4), which could prove stability of novel heterogeneous organocatalyst at the temperatures up to $80^{\circ} \mathrm{C}$. It was observed that catalytic activity of recycled immobilized NHPI was sometimes higher than the fresh one's. It is assumed that groups presented in solid catalyst that inhibit free radical reaction could be oxidized to inactive once during first usage.

The effect of temperature on oxidation of $p$-methoxytoluene and $\alpha$-methylstyrene in the presence of HEA/ DVB-NHPI was also examined. As expected, the oxygen uptake increased when temperature rose. However, the $\mathrm{O}_{2}$ consumption in comparison to blank reaction was lower at $90^{\circ} \mathrm{C}$ (1.45 times) than at $80^{\circ} \mathrm{C}$ (4.25 times) for $p$-methoxytoluene and at $80^{\circ} \mathrm{C}(1.1$ times $)$ than $70^{\circ} \mathrm{C}(1.3$ times $)$ for $\alpha$-methylstyrene. It shows that the rate of non-catalytic reactions is higher at the higher temperature.

The effect of amount of immobilized NHPI was studied in oxidation of $p$-methoxytoluene. HEA/DVB-NHPI at amount of $0.025,0.05$ and $0.15 \mathrm{~g}$ caused lower catalytic effect than $0.1 \mathrm{~g}$. An excessive amount of heterogeneous NHPI $(0.15 \mathrm{~g})$ in relation to $2 \mathrm{~mL}$ of reaction mixture caused worst effectiveness resulted in lower consumption of $\mathrm{O}_{2}$.

Obtained HEA/DVB-NHPI was also used in oxidation of $p$-methoxytoluene performed in acetic acid as a polar solvent (Table 1, entries 2-4). Previously reported NHPI immobilized on polystyrene by amide or ester bonds demonstrated significantly higher activity in the presence of polar solvent but the activity was lost during recycles [22]. It seemed that higher cross-linked novel HEA/DVB-NHPI would be more stable in solvent conditions. Over 160 times higher oxygen consumption in the process with novel heterogeneous NHPI than in oxidation without NHPI was observed. Unfortunately, catalytic activity of reused HEA/DVB-NHPI significantly decreased. FT-IR analysis of HEA/DVB-NHPI after second recycle in the solvent conditions (Fig. 5II) showed decreasing of the intensity of peaks at 1785,1785 and $1159 \mathrm{~cm}^{-1}$ assigned to the carbonyl group $(\mathrm{O}=\mathrm{C}(\mathrm{N}-$ $\mathrm{OH})$ ) and ester bonds $-\mathrm{C}-\mathrm{O}-$ (both in immobilized NHPI and in copolymer poly(HEA-co-DVB)). The signal of hydroxyl group at $3392 \mathrm{~cm}^{-1}$, presented in HEA/DVB spectrum (Fig. 1I) beforehand, was observed. Cleavage of the ester bonds in heterogeneous NHPI occurred in contrast to HEA/DVB-NHPI after second recycle in solvent-free system (Fig. 5III). Intensity of both signals of carbonyl groups
$\mathrm{O}=\mathrm{C}(\mathrm{O})$ at $1725 \mathrm{~cm}^{-1}$ and $\mathrm{O}=\mathrm{C}(\mathrm{NOH})$ at $1785 \mathrm{~cm}^{-1}$ was not changed. Furthermore, peak at $3218 \mathrm{~cm}^{-1}$ characteristic for $N$-hydroxyl group was strengthened.

The composition of products obtained in oxidation of $p$-methoxytoluene and $\alpha$-methylstyrene was determined by GC-FID analysis and presented in Table 3. $p$-Methoxytoluene was oxidized to $p$-methoxybenzaldehyde, $p$-methoxybenzyl alcohol and $p$-methoxybenzoic acid while main product of $\alpha$-methylstyrene oxidation was acetophenone.

\section{Conclusion}

This paper shows that immobilization of NHPI on copolymer poly(HEA-co-DVB) via ester bond has been successfully achieved. The structure of novel heterogeneous catalyst was confirmed by FT-IR and XPS spectroscopy and elemental analysis. Based on the results of elemental analysis the amount of immobilized NHPI and the crosslinking degree of carrier were calculated respectively $2.06 \mathrm{mmol}$ $\mathrm{NHPI} / \mathrm{g}$ and $6 \mathrm{~mol} \%$ of DVB. The amount of NHPI immobilized on investigated carrier is higher than on commercially available polystyrenes (MPS-NHPI: 0.35-1.65 mmol $\mathrm{NHPI} / \mathrm{g}$ ) [22] as well as on copolymer of glycidyl methacrylate and methyl methacrylate (GMA/MMA-NHPI: $1.1 \mathrm{mmol}$ NHPI/g) [23]. There is no data about NHPI loading of silica-supported NHPI [20, 21] and NDHPI immobilized on SBA-15 [24]. Additionally, the ester bond between active $N$-hydroxyl group and investigated carrier has got the ethyl-linker, which is longer than in polystyrene-based carrier [22].

HEA/DVB-NHPI was applied in oxidation $p$-methoxytoluene in $\mathrm{AcOH}$ as solvent. $\mathrm{O}_{2}$ consumption in comparison to NHPI loading of HEA/DVB-NHPI was $16 \mathrm{mmol}$ $\mathrm{O}_{2} / \mathrm{mmol} \mathrm{N}-\mathrm{OH}\left(\mathrm{Co}(\mathrm{II}), 80^{\circ} \mathrm{C}, 1 \mathrm{~atm}, 5 \mathrm{~h}\right.$ ). It was significantly higher than in comparison to previously reported silica-supported NHPI and Co(II) salt used in oxidation of toluene $\mathrm{O}_{2}$, when $\mathrm{O}_{2}$ uptake per NHPI loading was calculated as only $4.8 \mathrm{mmol} \mathrm{O} / \mathrm{mmol} \mathrm{NOH}\left(80^{\circ} \mathrm{C}, 1 \mathrm{~atm}, 20 \mathrm{~h}\right)$ [20]. Unfortunately, HEA/DVB-NHPI was unstable in AcOH due to degradation of the ester bonds in acidic media.

Activity of HEA/DVB-NHPI was also demonstrated in oxidation reactions of $p$-methoxytoluene and $\alpha$-methylstyrene in solvent-free system. When reaction was carried out without solvent recovery and recycling of immobilized NHPI were possible. In comparison to previously studies of chemically bonded NHPI [20-24], the obtained HEA/DVB-NHPI represented higher activity per mole of immobilized NHPI. Determined amount of $\mathrm{O}_{2}$ consumed per amount of immobilized NHPI was $3.3 \mathrm{mmol} \mathrm{O}_{2} / \mathrm{mmol}$ $\mathrm{N}-\mathrm{OH}$ and $2.7 \mathrm{mmol} \mathrm{O}_{2} / \mathrm{mmol} \mathrm{N}-\mathrm{OH}$ in $p$-methoxytoluene oxidation in the presence of novel HEA/DVBNHPI (2.06 mmol NHPI/g) and in previously described 
(chloromethyl)polystyrene-supported NHPI (1.65 mmol $\mathrm{NHPI} / \mathrm{g}$ ), respectively, under the same reaction conditions. However, as results of higher loading of NHPI and longer linker, higher oxygen uptake was achieved when HEA/ DVB-NHPI was used.

Acknowledgments Financial assistance from the National Science Centre of Poland (Grant No. N N209 755440) is gratefully acknowledged. Part of the research was done with equipment purchased in the frame of European Regional Development Fund (Polish Innovation Economy Operational Program-contract no. POIG.02.01.00-12-023/08).

Open Access This article is distributed under the terms of the Creative Commons Attribution 4.0 International License (http://creativecommons.org/licenses/by/4.0/), which permits unrestricted use, distribution, and reproduction in any medium, provided you give appropriate credit to the original author(s) and the source, provide a link to the Creative Commons license, and indicate if changes were made.

\section{References}

1. Recupero F, Punta C (2007) Chem Rev 107:3800

2. Coseri S (2009) Cat Rev Sci Eng 51:218

3. Chen K, Zhang P, Wang Y, Li H (2014) Green Chem 16:2344

4. Lin R, Chen F, Jiao N (2012) Org Lett 14:4158

5. Amorati R, Lucarini M, Mugnaini V, Pedulli GF, Minisci F, Recupero F, Fontana F, Astolfi P, Greci L (2003) J Org Chem 68:1747

6. Sheldon RA, Arends IWCE (2006) J Mol Catal A: Chem 251:200

7. Aoki Y, Hirai N, Sakaguchi S, Ishii Y (2005) Tetrahedron 61:10995

8. Coseri S (2009) Catal Rev 51:218

9. Aoki Y, Sakaguchi S, Ishii Y (2004) Adv Synth Cata 346:199

10. Arends IWCE, Sasidharan M, Kühnle A, Duda M, Jost C, Sheldon RA (2002) Tetrahedron 58:9055

11. Punta C, Rector CL, Porter NA (2005) Chem Res Toxicol 18:349

12. Tsujimoto S, Iwahama T, Sakaguchi S, Ishii Y (2001) Chem Commun (Camb) 22:2352

13. Tsujimoto S, Sakaguchi S, Ishii Y (2003) Tetrahedron Lett 44:5601

14. Minisci F, Gambarotti C, Pierini M, Porta O, Punta C, Recupero F, Lucarini M, Mugnaini V (2006) Tetrahedron Lett 47:1421

15. d'Acunzo F, Baiocco P, Galli C (2003) New J Chem 27:329

16. Sakaguchi S, Eikawa M, Ishii Y (1997) Tetrahedron Lett 38:7075

17. Yang G, Ma Y, Xu J (2004) J Am Chem Soc 126:10542

18. Yoshino Y, Hayashi Y, Iwahama T, Sakaguchi S, Ishii Y (1997) J Org Chem 62:6810

19. Hermans I, Van Deun J, Houthoofd K, Peeters J, Jacobs P A (2007) J Catal 251:204

20. Rajabi F, Clark JH, Karimi B, Macquarrie DJ (2005) Org Biomol Chem 3:725

21. Ishii Y, Takano M, Hirai N (2010) US Patent 0317869

22. Kasperczyk K, Orlinska B, Witek E, Latka P, Zawadiak J, Proniewicz L (2015) Catal Lett 145:1856
23. Gao B, Meng S, Yang X (2015) Org Process Res Dev 19:1374

24. Zhou M, Li X, Bao L, Yuan X, Luo H (2015) Catal Lett 2:383

25. Dhakshinamoorthy A, Alvaro M, Garcia H (2011) Chem Eur J $17: 6256$

26. Dhakshinamoorthy A, Alvaro M, Garcia H (2011) ACS Catal $1: 836$

27. Dhakshinamoorthy A, Alvaro M, Garcia H (2012) J Catal 289:259

28. Mikami Y, Dhakshinamoorthy A, Alvaro M, Garcia H (2013) Chem Cat Chem 5:1964

29. Yua P, Liub G, Tangb R (2014) Curr Organocatal 1:79

30. Rajabi F, Luque R, Clark JH, Karimi B, Macquarrie DJ (2011) Catal Commun 12:510

31. Chen L, Li B-D, Xu Q-X, Liu D-B (2013) Chin Chem Lett 24:849

32. Yua WH, Zhoub CH, Tongb DS, Xua TN (2012) J Mol Catal A Chem 365:194

33. Jafarpour M, Rezaeifard A, Yasinzadeh V, Kargar H (2015) RSC Adv. doi:10.1039/C5RA04718H

34. Matsumoto A (1995) Springer, Berlin Heidelberg pp 41-80

35. Monthearda J-P, Chatzopoulosa M, Daniel Ch (1992) J Macromol Sci Pol R 32:1

36. Horàk D, Jayakrishnan A, Arshady R (2003) In: Arshady R (ed) Polymers in medicine and biology, vol 1. Citus Books, London, pp 80-107

37. Horàk D (2006) In: Pethrick CA, Zaokov EE (eds) Handbook of polymer research, vol 19. Nova Science Publishers Inc, New York, pp 1-33

38. Moghdam MN, Pioletti DP (2015) J Biomed Mater Res Part B 00B:000

39. Meherchi L, Chabane Sari SM, Senoudi AR, Zargou S, Benmouna F (2015) J Mater Environ Sci 6:2221

40. Montheard JP, Chatzopoulos M, Chappard D (1992) J Macromol Sci. Macromol Rev 32:1

41. Wichterle O, Lim D (1960) Nature 185:117

42. Kunzler J, McGee J (1995) Chem Ind 16:651

43. Wichterle O (1972) US Patent 3,679,504

44. Kopeček J (2009) J Polym Sci A Polym Chem 47:5929

45. Basri M, Samsudin S, Bin Ahmad M, Razak CNA, Salleh AB (1999) Appl Biochem Biotech 81:205

46. Ayhan F, Ayhan H, Piskin E, Tanyolac A (2002) Bioresource Technol 81:131

47. Hamdy S, El-Sigeny S, Abou TM (2008) J Macromol Sci A 45:980

48. Serrano AA, Campillo Fernàndeza AJ, Gómez Ribellesa JL, Monleón PM, Gallego FG, Pissisb P (2004) Polymer 45:8949

49. Monleón PM, Gómez Ribelles JL, Serrano AA, Gallego FG, Suay AJ, Pissis P (2001) Polymer 42:4667

50. Santander-Borrego M, Green DW, Chirila TV, Andrew K, Whittaker AK, Blakey I (2014) J Polym Sci Pol Chem 52:1781

51. Okay O, Gurun C (1992) J Appl Polym Sci 46:401

52. Kasperczyk K, Orlinska B, Zawadiak J (2014) Cent Eur J Chem 12:1176

53. Konieczynska MD, Dai C, Stephenson CRJ (2012) Org Biomol Chem 10:4509

54. Krishnakumar V, Manohar S, Nagalakshmi R (2008) Spectrochim Acta A 71:110 